\title{
The incidence of MYB gene breaks in adenoid cystic carcinoma of the salivary glands and its prognostic significance
}

\author{
Martin Broz ${ }^{\mathrm{a}}$, Petr Steiner ${ }^{\mathrm{b}}$, Richard Salzmanª, Lukas Hauer', Ivo Starek
}

\begin{abstract}
Aims. To detect MYB gene breaks in adenoid cystic carcinoma (ACC) of the salivary glands and its correlation with prognosis and selected clinical parameters

Methods. MYB gene break was detected by FISH assay in 23 adenoid cystic carcinomas using formalin-fixed paraffinembedded blocks. The Kaplan-Meier survival analysis was used to estimate prognosis.

Results. Fifteen of 23 evaluated tumours were MYB positive and 8 MYB negative. The 10-year cumulative survival, respectively disease free interval, was $60.0 \%$, respectively $59.3 \%$, in MYB positive patients and $88.5 \%$, respectively $80.0 \%$, in MYB negative patients (long rank test, $P=0.23$ ). There were no significant differences in age, gender, perineural invasion, the presence of hematogenic or nodal metastases or degree of histopathological grading between MYB positive and MYB negative patients.

Conclusion. A tendency to differences in the survival of patients with ACC, depending on their MYB status. MYB negative patients were predisposed to better prognosis.
\end{abstract}

Key words: adenoid cystic carcinoma, MYB gene, salivary gland, prognosis

Received: November 27, 2015; Accepted with revision: April 27, 2016; Available online: May 12, 2016 http://dx.doi.org/10.5507/bp.2016.027

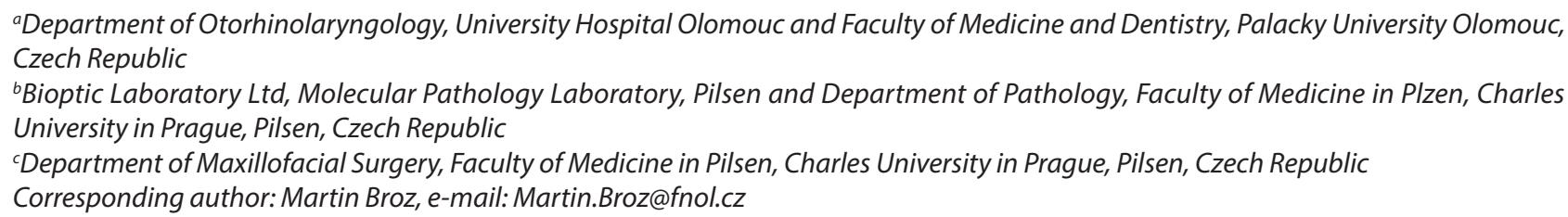

\section{INTRODUCTION}

Salivary gland tumours only account for about $1 \%$ of all human tumours. However, they represent a very specific cancer group characterized by great histomorphological diversity and variability of biological behavior, even within the same pathological entity, causing difficulties in determining prognosis. The severity of some salivary gland tumours is primarily given by their histopathologic diagnosis which is suggested by their grading (e.g. highly malignant small cell carcinoma vs. low-malignant acinic cell carcinoma). For other tumours (e.g. adenoid cystic carcinoma and mucoepidermoid carcinoma), special criteria were developed to determine their differentiation. For rare tumours without clinical-histopathologic correlations, there are no grading classifications established yet. In individual cases, however, the clinical course of the disease often does not match the specified histopathologic grade of malignancy. Therefore there is a tendency to divide salivary carcinomas into tumours with low- and high-risk rather than into lesions of low and high grade of malignancy. To predict local or regional recurrences of parotid carcinomas only, a score has been developed based solely on clinical data, without regard to histological type of tumour ${ }^{1}$.

However, this is complex and time-consuming and thus not used in routine practice.
Adenoid cystic carcinoma (ACC), the second or third most common cancer of major salivary glands and the prevailing malignancy of minor salivary glands $\mathrm{s}^{2,3}$, is a lesion with poorly predictable prognosis. It affects patients of any age, but mostly those in their fifth or sixth decade of life ${ }^{3}$. The poor prognosis results from often very difficult, and sometimes even impossible, resection of the entire tumour. Perineural spread is commonly responsible for difficulties in surgical removal. Incomplete resection frequently leads to a pronounced tendency to local, regional or distant recurrences. Moreover, a chronic course is typical with development of late hematogenic metastases, primarily affecting the lungs, liver or skeleton. These sometimes act indolently and patients often live for long time with confirmed recurrence ${ }^{4}$. In pathomorphological terms, this tumour is characterized by the presence of tubular, cribriform and solid structures. The relative proportion of the latter component has become a basis for the later modified histopathological grading ${ }^{5,6}$. Seethala ${ }^{7}$ points out, however, that its prognostic importance has not been clearly demonstrated and clinical stage continues to be the decisive prognostic factor for ACC (as with other cancers of the salivary glands). ACC that have undergone high-grade transformation are characterized by a rapid fatal course ${ }^{8}$.

Difficulties in predicting the clinical course of salivary cancers led to intensive search for new prognostic 
and predictive molecular markers. This mainly concerns identification of genes, or their products, responsible for the initiation, progression and metastasizing of various types of tumours. In addition, it is expected that their targeted biological blockade could improve the survival in prognostically severe, high-risk salivary tumours.

\section{Genetic abnormalities in salivary tumours}

Oncogenic alterations are caused by a variety of mechanisms. One of these is fusion translocation, leading to a generation of new genes. Genetic changes are assumed to be responsible for the development of up to $20 \%$ of all human neoplasms ${ }^{9}$. Of the broad histopathological spectrum of salivary tumours, genetic alterations have only been identified in 5 tumours.

Pleomorphic adenoma is initiated by a unique (and therefore important for histopathological differential diagnosis) fusion translocation of genes PLAG1 and HMGA2 $\left(\right.$ ref. $\left.{ }^{10}\right)$. Cancerization of this tumour is caused by amplification of MDM2, HMGA2-WIF1 and HER2 genes 9 . Translocation of CRTC1 and MAML2 genes is typical for mucoepidermoid carcinoma ${ }^{11}$. It has also prognostic importance, since it has been associated with longer survival time, fewer local recurrences, and a decreased tendency to metastasize ${ }^{12}$. Detection of the fusion genes ETV6 and NTRK3 (ref. ${ }^{13}$ ) has enabled the identification of mammary analogue secretory carcinoma (MASC) of the salivary glands, which was previously incorrectly diagnosed as biologically more favorable acinic cell carcinoma. Hyalising clear cell carcinoma is characterized by translocation between the ESWR1 and ATF1 genes ${ }^{14}$.

Adenoid cystic carcinoma is a salivary tumour in which genetic abnormalities were studied. Jian Fen $\mathrm{He}^{15}$ and Sasahira ${ }^{16}$ found a negative correlation between the expression of the RUNX3 suppressor gene and its prognosis. This tumour, like some other salivary carcinomas, is associated with increased but prognostically irrelevant expression of the c-kit oncoprotein and EGFR (ref. ${ }^{17-19}$ ).

Recent studies confirm that most ACCs are associated with an alteration of the MYB gene. The MYB gene is located in the g22-q23 region of chromosome 6 . Its protein product is a key transcription factor for the physiological regulation of stem cells in the bone marrow and in the intestinal crypts. Deregulation and aberrant function of this gene leads to the development of several malignant diseases. For instance in pediatric acute basophilic and lymphocytic leukemia, MYB-GATA1 translocation ${ }^{9,20,29}$ and recurrent chromosomal translocations and duplications in the MYB locus ${ }^{21}$ were identified.

The MYB gene alteration (MYB-NFIB translocation) is specific for ACC and has not been found in other salivary tumours or normal salivary glands ${ }^{22-25}$. It is noteworthy that opinions on the prognostic importance of this gene, and its expression, remain inconsistent. While Mitani ${ }^{25}$ and West $^{23}$ found a significant relationship to the survival and certain clinical parameters, other authors refute these relationships ${ }^{22}$. Therefore, we analyzed the presence of MYB gene breaks using FISH technique and evaluated their prognostic importance.

\section{MATERIALS AND METHODS}

\section{Clinical features of patients}

In the salivary gland tumour archive at the Šikl's Institute of Pathology in Pilsen, archived materials of 31 patients treated for ACC in the period from 1989 through 2014 were retrieved. Samples where relevant clinical data were not available or those where FISH assay was not interpretable were excluded from study. A total of 23 samples were analyzed.

The group included 9 males and 14 females. The age of the patients ranged from 24 to 84 (mean $55.7 \pm 16.1$ ) years. In total, 7 carcinomas were localized in parotid glands, 7 in submandibular glands, 2 in sublingual glands and 7 in minor salivary glands.

At the time of diagnosis, seven patients were at stage T1, 5 at stage T2, 6 at stage T3 and 5 at stage T4. Cervical lymph nodes were involved as follows: stage N1 metastases were found in 3 , and stage $\mathrm{N} 2 \mathrm{~b}$ metastases in two patients. Distant metastases were found in 1 patient. Two tumours were found to be well, 12 cases moderately, and 9 poorly differentiated. Clinical characteristics are shown in Table 1.

Six submandibular and 2 sublingual tumours were completely removed with the glands. Of the 7 parotid tumours, 6 were removed by total, and 1 by conservative parotidectomy. Two tumours of the 7 minor salivary glands were completely removed. In 10 , respectively 4 , out of 17 patients, the surgery was followed by adjuvant radiation therapy and/or chemoradiotherapy. Three patients were treated by surgery only. Of the remaining 5 patients, 2 were indicated for chemoradiotherapy, one for curative radiotherapy, one for palliative radiotherapy, and one patient received symptomatic treatment only.

The follow up interval ranged from 5.0 to 286.1 (mean $71.4 \pm 64.1)$ months. Of the total 23 patients, 21 achieved complete remission. Sixteen patients were alive at the conclusion of the study. One of them lived with signs of the disease. Six patients died. . The last died from cardiovascular disease.

\section{Detection of MYB break by FISH}

Four $\mu \mathrm{m}$ thick section was placed onto positively charged slide. Hematoxylin and eosin stained slides were examined for determination of areas for cell counting. The unstained slide was routinely deparaffinized and incubated in 1x Target Retrieval Solution Citrate pH 6 (Dako, Glostrup, Denmark) for $40 \mathrm{~min}$ at $95^{\circ} \mathrm{C}$ and subsequently cooled for $20 \mathrm{~min}$ at room temperature in the same solution. The slide was washed in deionized water for $5 \mathrm{~min}$ and digested in protease solution with Pepsin $(0.5 \mathrm{mg} /$ $\mathrm{mL}$ ) (Sigma Aldrich, St. Louis, MO, USA) in $0.01 \mathrm{M} \mathrm{HCl}$ at $37{ }^{\circ} \mathrm{C}$ for $30 \mathrm{~min}$. The slide was then placed in deionized water for $5 \mathrm{~min}$, dehydrated in a series of ethanol solution (70\%, 85\%, 96\% for 2 min each) and air-dried. Detection of the rearrangement of the MYB gene was performed using ZytoLight ${ }^{\circledR}$ SPEC MYB Dual Color Break Apart Probe (ZytoVision GmbH, Bremerhaven, Germany). An appropriate amount of factory premixed 
Table 1. Clinical characteristics of patients with ACC and their MYB status.

\begin{tabular}{|c|c|c|c|c|c|c|c|c|c|c|}
\hline Patient & Age & Primary tumour site & Sex & Stage & Grade & OAS & DFI & Death & Recurrence & $\begin{array}{c}\text { MYB } \\
\text { (FISH) }\end{array}$ \\
\hline 1. & 32 & submandibular & $\mathrm{m}$ & 1 & 2 & 33.5 & 32.2 & 0 & 0 & 1 \\
\hline 2. & 84 & minor & $\mathrm{m}$ & 4 & 3 & 9.1 & $\mathrm{X}$ & 1 & 0 & 1 \\
\hline 3. & 58 & minor & $\mathrm{f}$ & 2 & 2 & 97.4 & 95.4 & 0 & 0 & 1 \\
\hline 4. & 60 & minor & $\mathrm{f}$ & 1 & 2 & 59.8 & 20.1 & 0 & 1 & 1 \\
\hline 5. & 48 & minor & $f$ & 2 & 3 & 85.2 & 80.1 & 0 & 0 & 1 \\
\hline 6. & 48 & submandibular & $\mathrm{f}$ & 3 & 2 & 141.1 & 42.6 & 1 & 1 & 1 \\
\hline 7. & 47 & submandibular & $\mathrm{f}$ & 1 & 3 & 38.6 & 31.0 & 1 & 1 & 1 \\
\hline 8. & 65 & sublingual & $\mathrm{m}$ & 1 & 2 & 81.2 & 79.2 & 0 & 0 & 1 \\
\hline 9. & 45 & parotid & $\mathrm{m}$ & 3 & 2 & 46.7 & 41.6 & 0 & 0 & 0 \\
\hline 10. & 79 & minor & $\mathrm{f}$ & 4 & 2 & 5.1 & $\mathrm{x}$ & 1 & 0 & 1 \\
\hline 11. & 77 & parotid & $\mathrm{f}$ & 2 & 3 & 22.4 & 21.1 & 0 & 0 & 1 \\
\hline 12. & 49 & submandibular & $\mathrm{f}$ & 3 & 2 & 164.3 & 163.6 & 0 & 0 & 0 \\
\hline 13. & 76 & sublingual & $\mathrm{f}$ & 3 & 3 & 5.0 & 3.5 & 0 & 0 & 0 \\
\hline 14. & 51 & minor & $\mathrm{m}$ & 4 & 2 & 87.3 & 83.7 & 0 & 0 & 0 \\
\hline 15. & 24 & submandibular & $\mathrm{m}$ & 1 & 2 & 286.1 & 285.8 & 0 & 0 & 1 \\
\hline 16. & 65 & parotid & $\mathrm{f}$ & 3 & 1 & 73.2 & 70.2 & 0 & 0 & 0 \\
\hline 17. & 33 & submandibular & $\mathrm{m}$ & 1 & 2 & 65.3 & 65.1 & 0 & 0 & 0 \\
\hline 18. & 61 & submandibular & $\mathrm{f}$ & 2 & 3 & 27.4 & 26.8 & 0 & 0 & 1 \\
\hline 19. & 57 & minor & $\mathrm{m}$ & 4 & 3 & 23.9 & 7 & 1 & 1 & 1 \\
\hline 20. & 54 & parotid & $\mathrm{f}$ & 3 & 1 & 66.9 & 50.1 & 0 & 1 & 0 \\
\hline 21. & 34 & parotid & $\mathrm{m}$ & 3 & 2 & 39.6 & 36.5 & 0 & 0 & 1 \\
\hline 22. & 71 & parotid & $\mathrm{f}$ & 4 & 3 & 152 & 79.3 & 1 & 1 & 1 \\
\hline 23. & 64 & parotid & $\mathrm{f}$ & 1 & 3 & 34.8 & 32.2 & 1 & 0 & 0 \\
\hline
\end{tabular}

$\mathrm{x}$ - remission not achieved, DFI - disease free interval, OAS - overall survival.

probe was applied to the specimen, covered with a glass coverslip and sealed with rubber cement. The slide was incubated in the ThermoBrite ${ }^{\mathrm{TM}}$ instrument (StatSpin/ Iris Sample Processing, Westwood, MA, USA) with codenaturation parameters $85^{\circ} \mathrm{C}$ for $8 \mathrm{~min}$ and hybridization parameters $37{ }^{\circ} \mathrm{C}$ for $16 \mathrm{~h}$. The rubber cemented coverslip was then removed and the slide was placed in post-hybridization wash solution ( $2 x \mathrm{SSC} / 0.3 \% \mathrm{NP}-40)$ at $72{ }^{\circ} \mathrm{C}$ for $2 \mathrm{~min}$. The slide was air-dried in the dark, counterstained with 4',6'-diamidino-2-phenylindole DAPI (Vysis/Abbott Molecular, IL, USA), coverslipped and immediately examined.

The section was examined with an Olympus BX51 fluorescence microscope (Olympus Corporation, Tokyo, Japan) using a 100x objective and filter sets Triple Band Pass (DAPI / SpectrumGreen / SpectrumOrange), Dual Band Pass (SpectrumGreen / SpectrumOrange) and Single Band Pass (SpectrumGreen or SpectrumOrange). One hundred randomly selected nonoverlapping tumour cell nuclei were examined for yellow (normal) or green and orange (chromosomal breakpoint) fluorescent signals (Fig. 1). The cut off value was set to more than $10 \%$ of nuclei with chromosomal breakpoint signals (mean +3 standard deviation in normal non-neoplastic control tissues).

\section{Statistical methods of assessment}

Kaplan-Meier survival analysis was performed. Survivors were referred to as "censored". The difference between the overall survival and disease free interval in patients with MYB-positive and MYB-negative tumours was evaluated using the log-rank test. The status of this gene was correlated with age and gender of patients, the presence of nodal or distant metastases, perineural invasion and histopathological grading using the chi square test. The statistical significance was set at $P=0.05$.

\section{RESULTS}

Of the total of 23 examined patients with ACC, MYB gene breaks were identified in 15 (i.e. $65 \%$ ) of patients.

The study showed no statistically significant differences between MYB positive and MYB negative patients for age, gender, tumour extent, presence of nodal or hematogenic metastases, histopathological grading, perineural invasion $(P>0.05$, chi square test, see Table 2$)$.

The overall survival ranged from 5.1 to 286.1 (mean 73.5 \pm 74.1 , median 39.6) months in MYB-positive patients, and from 5.0 to 164.3 (mean $67.9 \pm 46.6$, median 66.1) in MYB negative patients. The 10-year cumulative over allsurvival rate was $60.0 \%$ for MYB-positive and $88.5 \%$ for MYB-negative patients (log rank test, $P=0.23$, Fig. 2).

The disease free interval ranged from 7.0 to 285.8 (mean 64.4 \pm 72.2 , median 36.5) months in MYB-positive patients, and from 3.5 to 163.6 (mean $63.7 \pm 47.7$, median 57.6) in MYB negative patients. The 10-year cumulative overall survival rate was 59.3\% for MYB-positive (and $80.0 \%$ for MYB-negative patients ( $\log$ rank test, $P=0.21$, Fig. 3). 
Table 2. Correlation of the MYB status with selected clinical and histopathological parameters of ACC.

\begin{tabular}{|c|c|c|c|}
\hline & MYB+ & MYB - & $P$ \\
\hline \multicolumn{4}{|l|}{ Age } \\
\hline under 50 & 9 & 5 & 0.63 \\
\hline up 50 & 6 & 3 & \\
\hline \multicolumn{4}{|l|}{ Sex } \\
\hline males & 6 & 3 & 0.63 \\
\hline females & 9 & 5 & \\
\hline \multicolumn{4}{|l|}{ Primary site } \\
\hline minor & 6 & 1 & 0.18 \\
\hline major & 9 & 7 & \\
\hline \multicolumn{4}{|l|}{ Stage } \\
\hline $1+2$ & 2 & 6 & 0.12 \\
\hline $3+4$ & 9 & 6 & \\
\hline \multicolumn{4}{|l|}{ Nodal status } \\
\hline positive & 2 & 3 & 0.28 \\
\hline negative & 12 & 6 & \\
\hline \multicolumn{4}{|c|}{ Distant spread } \\
\hline yes & 1 & 0 & 0.65 \\
\hline no & 14 & 8 & \\
\hline \multicolumn{4}{|l|}{ Grade } \\
\hline $\mathrm{I}+\mathrm{II}$ & 8 & 6 & 0.29 \\
\hline III & 7 & 2 & \\
\hline \multicolumn{4}{|l|}{ PNI } \\
\hline yes & 3 & 1 & 0.60 \\
\hline no & 1 & 1 & \\
\hline
\end{tabular}

PNI - perineural invasion.

\section{DISCUSSION}

In ACC, an alteration of the MYB was first described in 2009 by Persson ${ }^{26}$ in 6 patients in whom tumours originated in major and minor salivary glands, lacrimal glands and breast. All these cases involved a translocation of the MYB gene and its fusion with a small portion NFIB gene which is located on chromosome 9 in the p23-p24 region. The author therefore believed that this fusion translocation, which is known to increase the MYB transcription activity of tumour cells ${ }^{27}$, is the sole mechanism of ACC.

Other studies ${ }^{23,24,28}$, examining MYB-NFIB fusion and the immunohistochemical expression of this fusion gene, demonstrated that the immunohistochemical expression is not always increased. Thus, it is assumed that the MYB gene is also activated by other, not yet completely explained mechanisms ${ }^{24}$. Using the FISH technique, West $^{23}$ found abnormal condition of the MYB gene in $16 \%$ of cases in his group of patients with ACC. The authors believed a duplication was involved, which was not associated with the NFIB gene. Similar findings were observed in patients with acute T cell lymphocytic leuke$\mathrm{mia}^{21}$. Another possibility of the MYB gene alteration is the break demonstrated by us, which occurred in $65 \%$ of the analyzed samples. Such gene anomaly has not been described to date.

Our study suggests the prognostic relevance of the MYB gene break. A tendency to prolonged survival was seen in MYB-negative patients. A larger cohort might

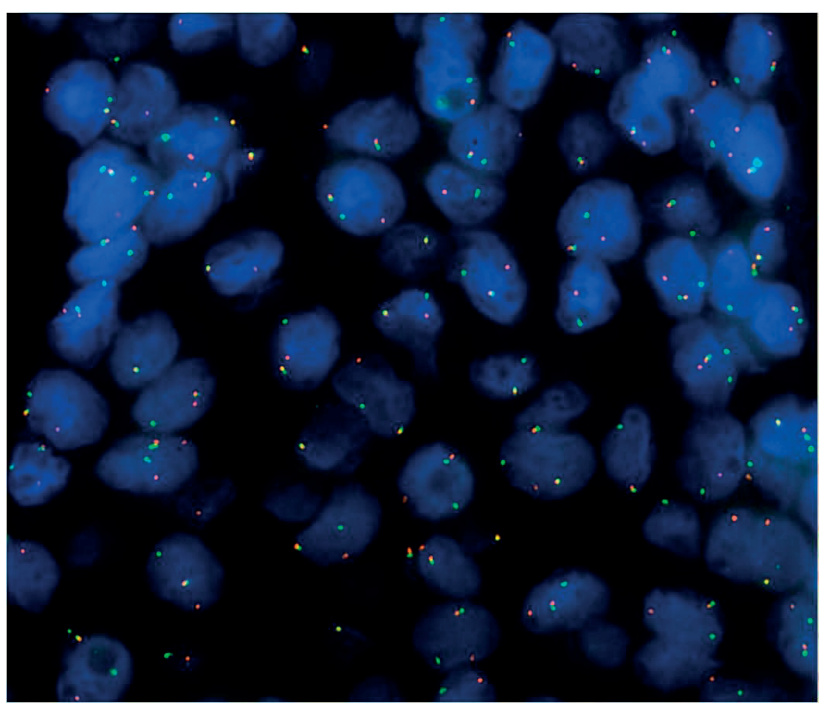

Fig. 1. FISH MYB positive reactions in ACC patients.

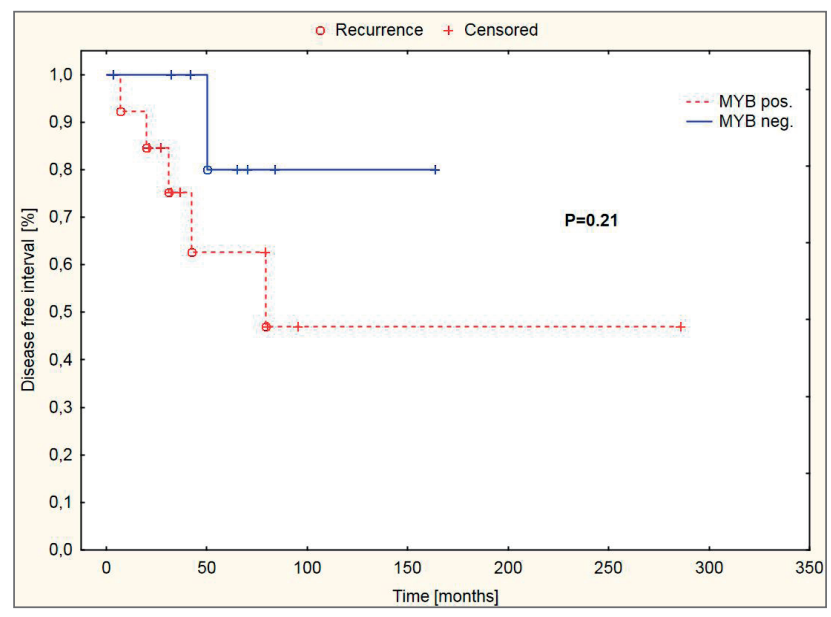

Fig. 2. The overall survival and MYB status in patients with ACC.

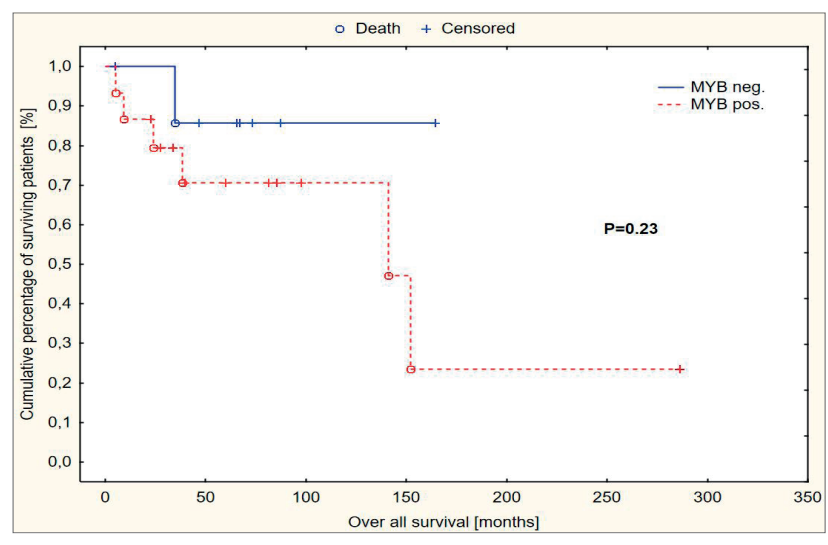

Fig. 3. Disease free interval and MYB status in patients with ACC.

provide a statistically significant difference. West ${ }^{23}$ and Mitani ${ }^{24,25}$ examined the prognostic importance of the MYB-NFIB fusion. In their group of ACC patients, this occurred in $49 \%$ and $28 \%$ of the examined samples, respectively. The first author found a lower survival rate 
in patients with this alteration. However, the result did not reach the statistical significance possibly due to small sample. The second author studied the prognostic impact of the presence of the MYB-NFIB fusion translocation in ACC patients in two consecutive trials. The first study involving 72 subjects showed a noticeable, however insignificant difference ${ }^{24}$ in OAS between patients with MYB-NFIB positive and negative tumours. Statistical relevance ${ }^{25}$ was achieved in the second study involving 103 cases.

Distant metastases were found only in one out of 23 patients. In this patient, we demonstrated break of the MYB gene. On the other hand, 14 patients with this alteration remained free of any evidence of tumour generalization. In the West's group ${ }^{23}$, hematogenous metastasis occurred only in two out of 37 patients with ACC. No MYB/NFIB fusion was demonstrated in either of the two above-mentioned patients, but it was present in 24 out of 35 metastasis-free patients.

Nodal metastases were detected in 5 of our patients, of whom 2 were MYB FISH positive. Of the total of 15 patients with this alteration, carcinoma was detected in the nodes only in 2 cases. West's study ${ }^{23}$ included 7 patients with nodular involvement, 4 of whom were MYB/NFIB positive. Four out of 18 patients in his cohort had nodal metastases. The results of both studies suggest that neither of these gene alterations is related to the lymphogenic or hematogenous spread of the tumour.

In this study, 3 out of 4 patients with perineural invasion (PNI) were MYB FISH positive. These 3 patients accounted for $20 \%$ of the total number of 15 patients with positive MYB gene break. In contrast, West ${ }^{23}$ reported on PNI invasion in 15 of 18 patients in his group i.e. $83 \%$ of MYB FISH positive patients. Our study, unlike the West's study, suggests a trend to perineural invasion in patients with the reported changes in this gene.

Our study revealed that 6 patients with minor salivary gland tumours were MYB positive. These six patients accounted for $84 \%$ of the total 7 tumours originating in minor salivary glands. Similarly in his study, West ${ }^{23}$ reported on 17 MYB-NFIB positive out of the total 24 patients with ACC of minor salivary glands.

NFIB is still the only identified partner for the MYB gene. We can therefore assume that the MYB positive patients have NFIB fusion at the same time. However, we cannot rule out that the MYB gene has yet unknown additional fusion partners, which may have a significant prognostic or predictive relevance.

\section{CONCLUSION}

The study showed a MYB gene break in $65 \%$ of ACC cases. MYB status very likely plays a role in the biological nature of ACC. A tendency to different prognosis (both over all survival and disease free interval) was apparent, unfortunately, without significant possibly due to low figures resulting from scarcity of this pathological entity. The MYB gene appears not to effect traditional prognostic factors such as TNM classification or tumour differen- tiation. Subsequent studies are required to elucidate its involvement in ACC.

\section{ABBREVIATIONS}

ACC, adenoid cystic carcinoma; PNI, perineural invasion.

Acknowledgement: This study was supported by the Institutional Support of the Ministry of Health, Czech Republic, Nr. 1RVO-FNOL2014, RVO: 61989592, and the Internal Grant Agency of the Ministry of Health, Czech Republic, Nr. NT13701-4/2012.

Autor contributions: All autors contributed equally to preparing the manuscript.

Coflict of interest statement: None declared.

\section{REFERENCES}

1. Vander Poorten VL, Balm AJ, Hilgers FJ, Tan IB, Loftus Coll BM, Keus $\mathrm{RB}$, Hart AA. The development of a prognostic score for patients with parotid carcinoma. Cancer 1999;85(9):2057-67.

2. Milano A, Longo,F, Basile M, laffaioli RV, Caponigro, F. Recent advances in the treatment of salivary gland cancers: emphasis on molecular targeted therapy. Oral oncology 2007;43(8):729-34.

3. Gondivkar SM, Gadbail AR, Chole R, Parikh RV. Adenoid cystic carcinoma: a rare clinical entity and literature review. Oral oncol 2011;47(4):231-6.

4. Speight PM, \& Barrett AW. Salivary gland tumours. Oral diseases 2002;8(5):229-40.

5. Szanto PA, Luna MA, Tortoledo ME, White RA. Histologic grading of adenoid cystic carcinoma of the salivary glands. Cancer 1984;54(6):1062-9.

6. Spiro RH, Huvos AG. Stage means more than grade in adenoid cystic carcinoma. Am J Surg 1992;164(6):623-8.

7. Seethala R.R. An update on grading of salivary gland carcinomas. Head Neck Pathol 2009;3(1):69-77.

8. Seethala RR, Hunt JL, Baloch ZW, LiVolsi VA, Barnes EL. Adenoid cystic carcinoma with high-grade transformation: a report of 11 cases and a review of the literature. Am J Surg Pathol 2007;31(11):1683-94.

9. Weinreb I. Translocation-associated salivary gland tumours: a review and update. Adv Anat Pathol 2013;20(6):367-77.

10. Geurts JM, Schoenmakers EF, Röijer E, Aström AK, Stenman G, van de Ven WJ. Identification of NFIB as recurrent translocation partner gene of HMGIC in pleomorphic adenomas. Oncogene 1998;16(7):865-72.

11. Behboudi A, Enlund F, Winnes, Nordkvist A, Leivo I, Flaberg E, Szekely L, Mäkitie A, Grenman R, Mark J, Stenman G. Molecular classification of mucoepidermoid carcinomas-Prognostic significance of the fusion oncogene. Genes Chromosomes Cancer 2006;45(5):470-81.

12. Hellquist $H$, Skalova $A$. Histopathology of the salivary glands. In: miscellaneous. Springer 2014; $p$ 430-431.

13. Skálová A, Vanecek T, Sima R, Laco J, Weinreb I, Perez-Ordonez B, Michal, M. Mammary analogue secretory carcinoma of salivary glands, containing the ETV6-NTRK3 fusion gene: a hitherto undescribed salivary gland tumour entity. Am J Surg Pathol 2010;34(5):599-608.

14. Antonescu CR, Zhang L, Chang NE, Pawel BR, Travis W, Katabi N, Fletcher CD. EWSR1-POU5F1 fusion in soft tissue myoepithelial tumours. A molecular analysis of sixty-six cases, including soft tissue, bone, and visceral lesions, showing common involvement of the EWSR1 gene. Genes Chromosomes Cancer 2010;49(12):1114-24.

15. Sasahira T, Kurihara M, Yamamoto K, Bhawal UK, Kirita T,Kuniyasu $\mathrm{H}$. Downregulation of runt-related transcription factor 3 associated with poor prognosis of adenoid cystic and mucoepidermoid carcinomas of the salivary gland. Cancer Sci 2011;102(2):492-7. 
16. He JF, Ge MH., Zhu X., Chen C, Tan, Z, Li YN, Gu ZY. Expression of RUNX3 in salivary adenoid cystic carcinoma: implications for tumour progression and prognosis. Cancer Sci 2008; 99(7):1334-40.

17. Stárek I, Kučerová L, Skálová A, Brož M, Bakaj T, Langová K Imunohistochemická exprese C-kit onkoproteinu u karcinomů slinných žláz (pilotní studie). Otorinolaryngologie a foniatrie 2010;(3):129-35.

18. Stárek I, Kučerová L, Skálová A, Brož M, Bakaj T, Zapletalová A, Hostička L. Imunohistochemická exprese onkoproteinu EGFR a její prognostický význam u karcinomů slinných žláz. Otorinolaryngologie a foniatrie 2011;2:78-84.

19. Lee SK, Kwon MS, Lee YS, Choi, SH, Kim, SY, Cho KJ, Nam, SY. Prognostic value of expression of molecular markers in adenoid cystic cancer of the salivary glands compared with lymph node metastasis: a retrospective study. World J Surg Oncol 2012;10:266.

20. Pattabiraman DR, Gonda TJ. Role and potential for therapeutic targeting of MYB in leukemia. Leukemia 2013;27(2):269-77.

21. Clappier E, Cuccuini W, Kalota A, Crinquette A, Cayuela JM, Dik WA Soulier J. The C-MYB locus is involved in chromosomal translocation and genomic duplications in human T-cell acute leukemia (T-ALL), the translocation defining a new T-ALL subtype in very young children. Blood 2007;110(4):1251-61.

22. Bell D, Roberts D, Karpowicz M, Hanna EY, Weber RS, El-Naggar AK. Clinical significance of Myb protein and downstream target genes in salivary adenoid cystic carcinoma. Cancer Biol Ther 2011;12(7):56973.
23. West RB, Kong C, Clarke N, Gilks T, Lipsick J, Cao H, Le,QT. MYB expression and translocation in adenoid cystic carcinomas and other salivary gland tumours with clinicopathologic correlation. Am J Surg Pathol 2011:35(1):92.

24. MitaniY, Li J, Rao PH, ZhaoYJ, Bell D, Lippman SM, El-Naggar AK. Comprehensive analysis of the MYB-NFIB gene fusion in salivary adenoid cystic carcinoma: Incidence, variability, and clinicopathologic significance. Clin Cancer Res 2010;16(19):4722-31.

25. Mitani Y, Rao PH, Futreal PA, Roberts DB, Stephens PJ, Zhao YJ, ElNaggar AK. Novel chromosomal rearrangements and break points at the $t(6 ; 9)$ in salivary adenoid cystic carcinoma: association with MYB-NFIB chimeric fusion, MYB expression, and clinical outcome. Clin Cancer Res 2011;17(22):7003-14.

26. Persson M, Andrén Y, Mark J, Horlings, HM, Persson F, Stenman, G. Recurrent fusion of MYB and NFIB transcription factor genes in carcinomas of the breast and head and neck. Proceedings of the National Academy of Sciences 2009;106(44):18740-4.

27. Moskaluk CA. Adenoid cystic carcinoma: clinical and molecular features. Head Neck Pathol 2013;7(1):17-22.

28. Brill LB, Kanner WA, Fehr A, Andrén Y, Moskaluk, CA, Löning, T, Frierson HF. Analysis of MYB expression and MYB-NFIB gene fusions in adenoid cystic carcinoma and other salivary neoplazma. Mod Pathol 2011;24(9):1169-76.

29. Belloni E, Shing D, Tapinassi C, Viale A, Mancuso P, Malazzi O, Pelicci PG. In vivo expression of an aberrant MYB-GATA1 fusion induces leukemia in the presence of GATA1 reduced levels. Leukemia $2011 ; 25(4): 733$ 